\title{
COMPARATIVE STRUCTURAL ANALYSIS OF OVERHEAD WATER TANK FOR DIFFERENT HEIGHT
}

\author{
Prasad D. Konde ${ }^{1}$, Bharati Changhode ${ }^{2}$ \\ P.G. Student, Department of Civil Engineering, G. H. Raisoni University, Amravati, Maharashtra, India ${ }^{1}$ \\ Assistant Professor, Department of Civil Engineering, G. H. Raisoni University, Amravati, Maharashtra, India ${ }^{2}$ \\ Email: $\left\{{ }^{1}\right.$ prasad.kondepk2014@gmail.com $\}$
}

\begin{abstract}
Water tanks are an important municipal and industrial structure. The design and construction methods used in reinforced concrete are influenced by the prevailing construction practices, physical properties of the material and climatic conditions. Before starting the design, the most appropriate type of tank installation and the correct assessment of loads are made, including the static balance of the structure, especially with regard to the overturning of overhanging elements. The work presented in the research work consists of a comparative analysis of the upper water tank in terms of shear force, bending moment and other parameters. From the results it is observed that the model-3 has the highest moment $(\mathrm{kNm})$ as compared to the other models and have the maximum value of $170 \mathrm{kNm}$ and the minimum value of $90 \mathrm{kNm}$ for model-7.
\end{abstract}

Keywords: Hydrodynamic Pressure, Elevated Water Tank, STAAD Pro V8i.

\section{Introduction}

Storage tanks and the upper tank are used to store water, liquid oil, petroleum products and similar liquids. These structures are made of masonry, steel, reinforced concrete and prestressed concrete. Of these, masonry and steel tanks are used for lower capacity. The cost of steel tanks is high, and therefore they are rarely used for water storage. Reinforced concrete tanks are high, and therefore they are rarely used for water storage. Reinforced concrete tanks are very popular because, in addition to simple structures and structures, they are cheap, monolithic in nature and can be protected from leaks.

As a rule, cracks are not allowed to form in any part of the structure of liquid-retaining tanks, and they are made watertight using a richer mixture (not less than M20) of concrete. In addition, sometimes waterproof materials are also used to make watertight tanks. The permeability of concrete is directly proportional to the water-cement ratio.

\section{Review of Literature}

Saleth, R.M [1] studied that the moment of the column in the reinforcement increases due to the increase in the height of the water tank. The moment of a column is minimum for radial fastening. The shear force in the mount increases by increasing the height of the setting. The shear force in the mount is minimal for radial mounting.

Issar Kapadia. et al. [6] investigated that for the same capacity, the same geometry, the same height, with the same system of setting, in the same Zone, with the same importance factor and the reduction factor of the reaction; the reaction of the equivalent static method to the dynamic one differs significantly.

Nallanathel. M. et al. [9]. Static analysis of the interaction of the water structure shows that both water and structure achieve selection at the same time due to the assumption that water sticks to the container and acts as the structure itself, and the structure and water have the same stiffness, while in dynamic analysis we considered two mass models.

\section{Modeling}

The modeling is carried out in the STAAD software, mentioned as follows.

- Model-I: Rectangular water tank-6m height by IS code

- Model-II: Rectangular water tank-9m height by IS code

- Model-III: Rectangular water tank-12m height by IS code

- Model-IV: Rectangular water tank-6m height by ACI code

- Model-V: Rectangular water tank-9m height by ACI code

- Model-VI: Rectangular water tank-12m height by ACI code

- Model-VII: Rectangular water tank-6m height by British code

- Model-VIII: Rectangular water tank-9m height by British code

- Model-IX: Rectangular water tank-12m height by British code

- Model-X: Rectangular water tank-15m height by IS code 
Table 1: Properties of Model-I \& IV

\begin{tabular}{|l|l|}
\hline Particulars & Dimension \\
\hline Plan dimension of water tank & $4.0 \mathrm{~m} \mathrm{X} \mathrm{6.0} \mathrm{m}$ \\
\hline Depth of water tank & $2.0 \mathrm{~m}$ \\
\hline Thickness of water tank & $200 \mathrm{~mm}$ \\
\hline Height of Column & $6.0 \mathrm{~m}$ \\
\hline Size of Beam & $350 \mathrm{~mm} \mathrm{X} \mathrm{500} \mathrm{mm}$ \\
\hline Size of Column & $400 \mathrm{~mm} \mathrm{X} \mathrm{600} \mathrm{mm}$ \\
\hline
\end{tabular}

Table 2: Properties of Model-II \& V

\begin{tabular}{|l|l|}
\hline Particulars & Dimension \\
\hline Plan dimension of water tank & $4.0 \mathrm{~m} \mathrm{X} \mathrm{6.0} \mathrm{m}$ \\
\hline Depth of water tank & $2.0 \mathrm{~m}$ \\
\hline Thickness of water tank & $210 \mathrm{~mm}$ \\
\hline Height of Column & $9.0 \mathrm{~m}$ \\
\hline Size of Beam & $350 \mathrm{~mm} \mathrm{X} \mathrm{500} \mathrm{mm}$ \\
\hline Size of Column & $450 \mathrm{~mm} \mathrm{X} \mathrm{650} \mathrm{mm}$ \\
\hline
\end{tabular}

Table 3: Properties of Model-III \& VI

\begin{tabular}{|l|l|}
\hline Particulars & Dimension \\
\hline Plan dimension of water tank & $4.0 \mathrm{~m} \mathrm{X} \mathrm{6.0} \mathrm{m}$ \\
\hline Depth of water tank & $2.0 \mathrm{~m}$ \\
\hline Thickness of water tank & $220 \mathrm{~mm}$ \\
\hline Height of Column & $12.0 \mathrm{~m}$ \\
\hline Size of Beam & $350 \mathrm{~mm} \mathrm{X} \mathrm{550} \mathrm{mm}$ \\
\hline Size of Column & $450 \mathrm{~mm} \mathrm{X} \mathrm{750} \mathrm{mm}$ \\
\hline
\end{tabular}

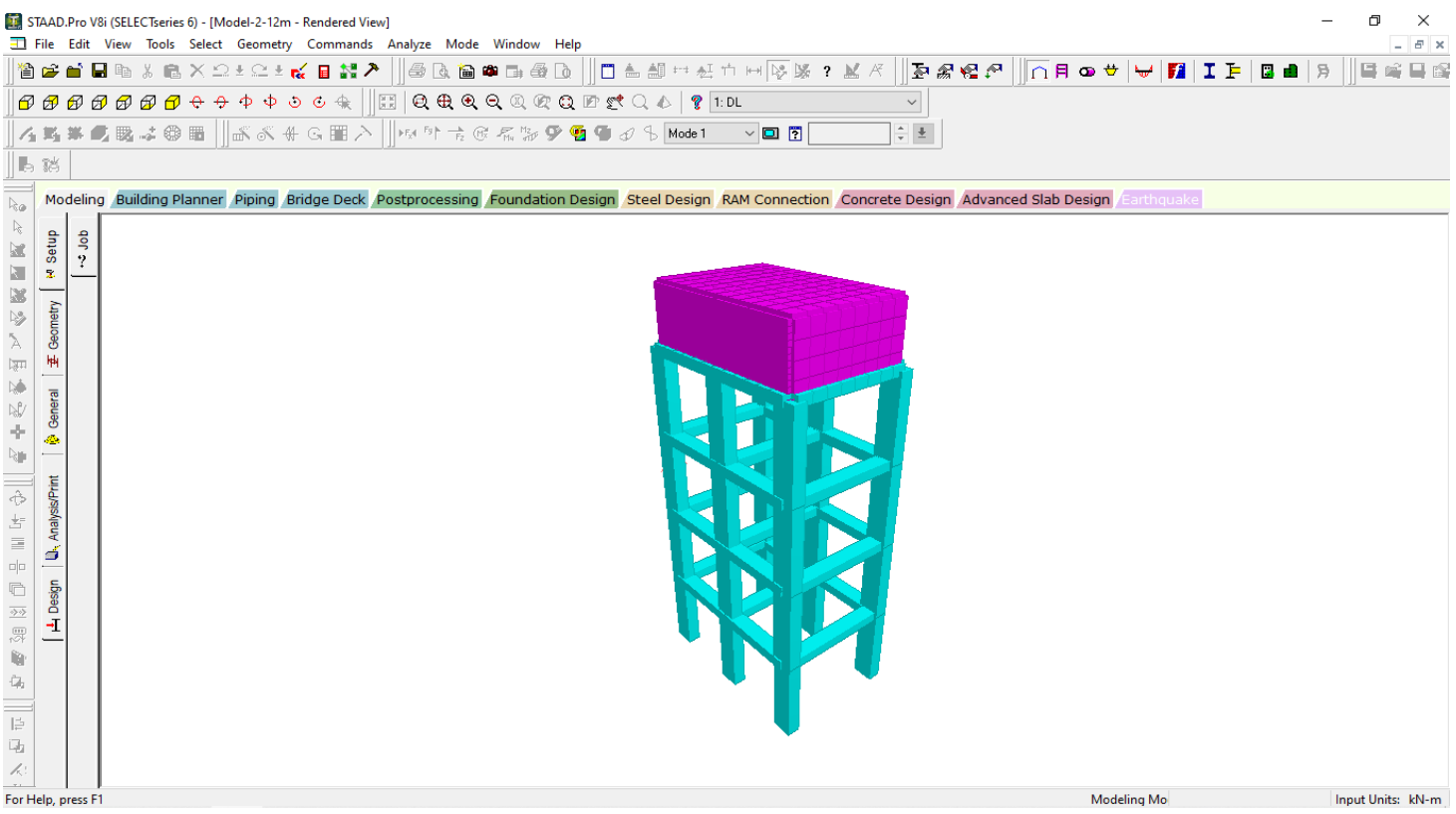

Fig. 1 Elevation of Model-III 


\section{Results}

The analysis is carried out in STAAD software and the results in terms of shear force, bending moment and other parameter is obtained as follows.

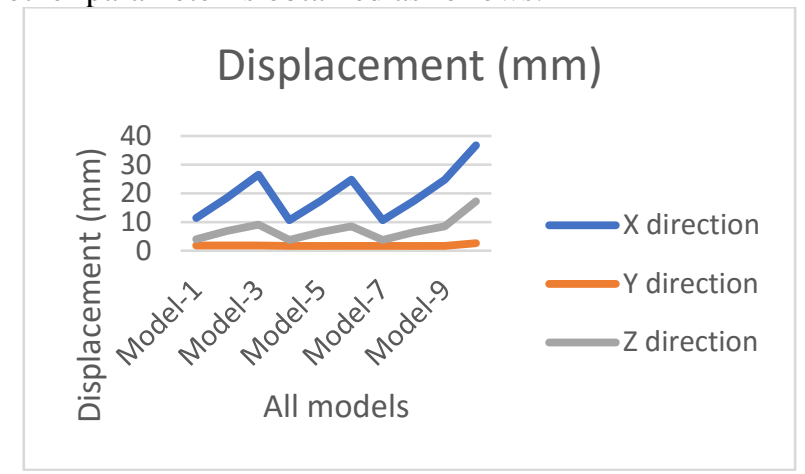

Fig. 2 Displacement for all the models

From the above Fig. 2 it is observed that the model-10 has the highest displacement as compared to the other models and have the maximum value of $37 \mathrm{~mm}$.

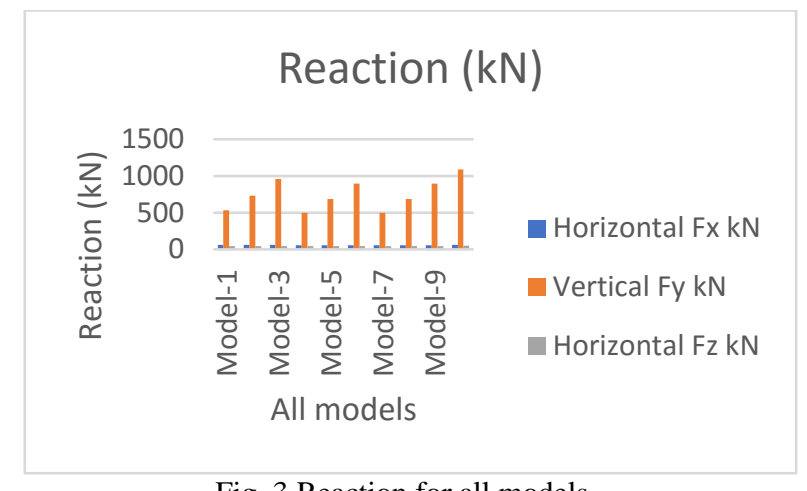

Fig. 3 Reaction for all models

From the above Fig. 3 it is observed that the model-10 has the highest reaction $(\mathrm{kN})$ as compared to the other models and have the maximum value of $1100 \mathrm{kN}$ and the minimum value of $500 \mathrm{kN}$ for model-4.

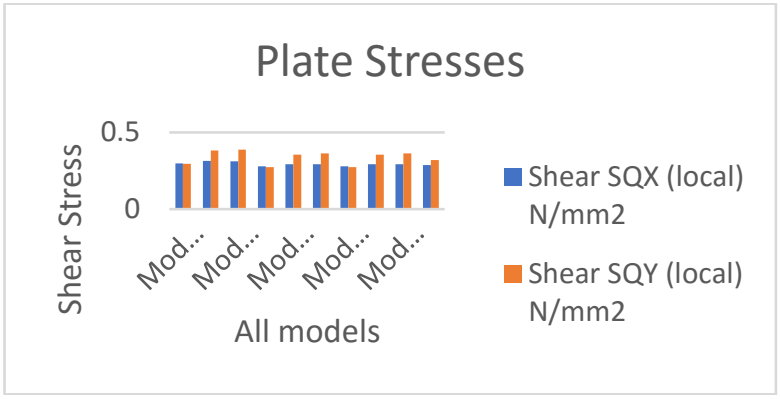

Fig. 4 Plate stresses for all models

From the above Fig. 4 it is observed that the model-3 has the highest Plate stresses $\left(\mathrm{N} / \mathrm{mm}^{2}\right)$ as compared to the other models and have the maximum value of $0.4 \mathrm{~N} / \mathrm{mm}^{2}$ and the minimum value of $0.275 \mathrm{~N} / \mathrm{mm}^{2}$ for model-4.

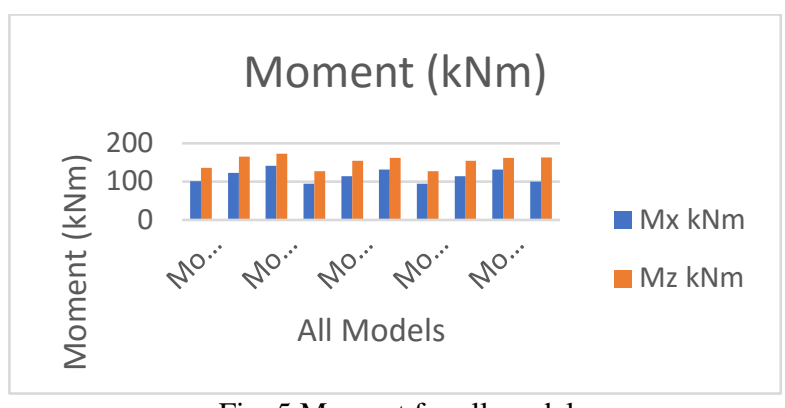

Fig. 5 Moment for all models

From the above Fig. 5 it is observed that the model-3 has the highest moment $(\mathrm{kNm})$ as compared to the other models and have the maximum value of $170 \mathrm{kNm}$ and the minimum value of $90 \mathrm{kNm}$ for model-7.

\section{Plate Stresses}

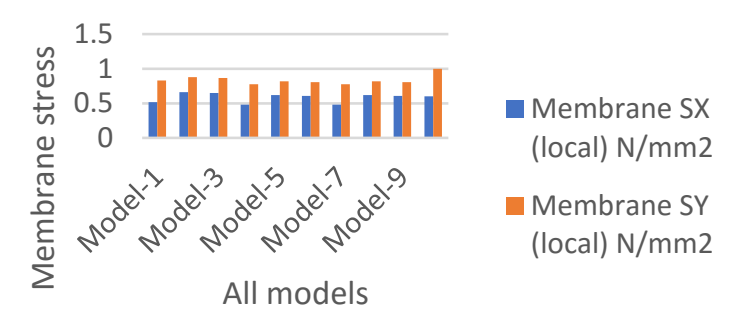

Fig. 6 Plate stresses for all models

From the above Fig. 6 it is observed that the model-10 has highest the membrane stress $\left(\mathrm{N} / \mathrm{mm}^{2}\right)$ as compared to the other models and have the maximum value of $1 \mathrm{~N} / \mathrm{mm}^{2}$ and the minimum value of $0.5 \mathrm{~N} / \mathrm{mm}^{2}$ for model- 7 .

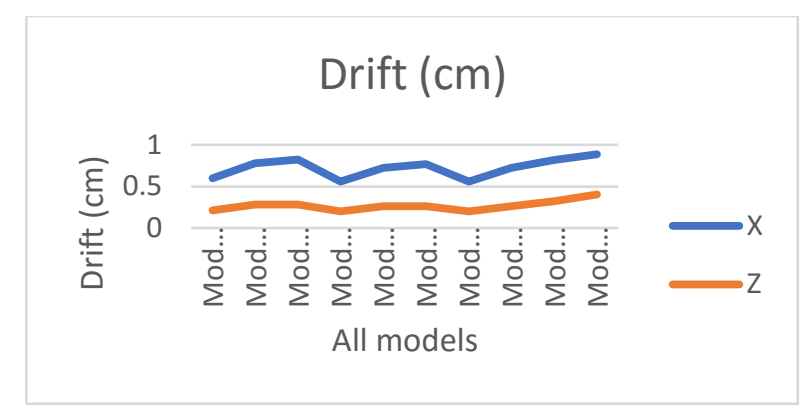

Fig. 7 Drift for all models

From the above Fig.7 it is observed that the model-10 has the highest drift ( $\mathrm{mm}$ ) as compared to the other models and have the maximum value of $0.9 \mathrm{~cm}$ and the minimum value of $0.5 \mathrm{~cm}$ for model- 7 .

\section{Average Displacement $(\mathrm{cm})$}

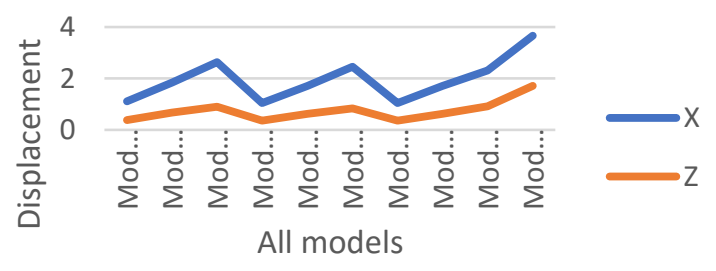

Fig. 8 Average Displacement for all models
JREAS, Vol. 06, Issue 03, July 2021 
From the above Fig. 8 it is observed that the model-10 has the highest Average Displacement $(\mathrm{cm})$ as compared to the other models and have the maximum value of $3.6 \mathrm{~cm}$ and the minimum value of $1.0 \mathrm{~cm}$ for model -7 .

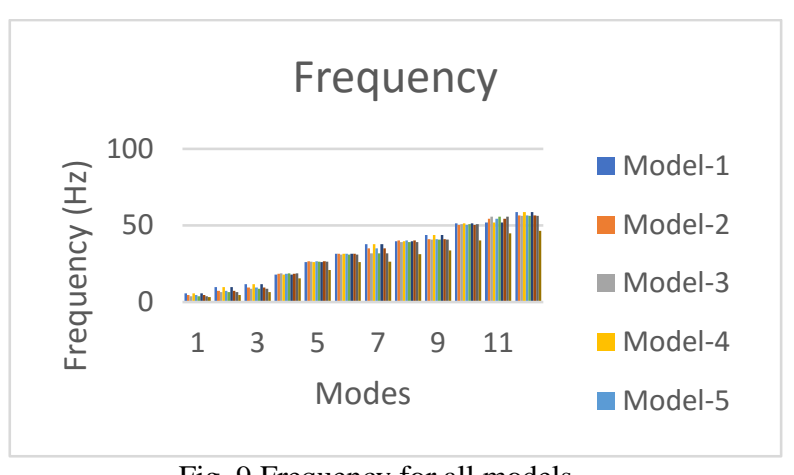

Fig. 9 Frequency for all models

From the above Fig. 9 it is observed that the model-7 has the highest Frequency as compared to the other models and have the maximum value of $60 \mathrm{~Hz}$.

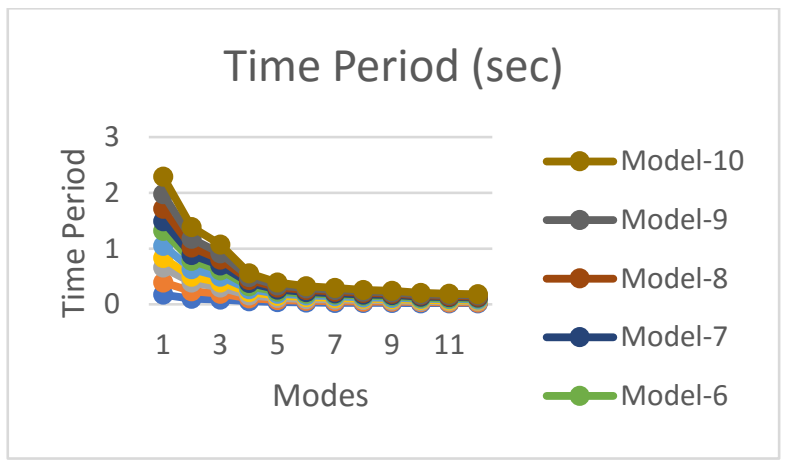

Fig. 10 Time Period for all models

From the above Fig. 10 it is observed that the model-10 has the Time Period (sec) as compared to the other models and have the maximum value of $2.25 \mathrm{sec}$ and the minimum value of $0.1 \mathrm{sec}$ for model-1.

\section{Conclusion}

The conclusions from the above study are as follows:

i. From the above results it is observed that the model-3 has the highest moment $(\mathrm{kNm})$ as compared to the other models and have the maximum value of $170 \mathrm{kNm}$ and the minimum value of $90 \mathrm{kNm}$ for model-7.

ii. From the above results it is observed that the model-10 has the membrane stress $(\mathrm{N} / \mathrm{mm} 2)$ as compared to the other models and have the maximum value of $1 \mathrm{~N} / \mathrm{mm} 2$ and the minimum value of $0.5 \mathrm{~N} / \mathrm{mm} 2$ for model- 7 .

iii. From the above results it is observed that the model-10 has the drift ( $\mathrm{mm}$ ) as compared to the other models and have the maximum value of $0.9 \mathrm{~cm}$ and the minimum value of $0.5 \mathrm{~cm}$ for model- 7 .

iv. From the above results it is observed that the model-10 has the Average Displacement (cm) as compared to the other models and have the maximum value of $3.6 \mathrm{~cm}$ and the minimum value of $1.0 \mathrm{~cm}$ for model- 7 .

ISSN (Print): 2456-6411 | ISSN (Online): 2456-6403 v. From the above results it is observed that the model-7 has the highest Frequency as compared to the other models and have the maximum value of $60 \mathrm{~Hz}$.

\section{Reference}

[1] Saleth, R.M., 2004. Strategic analysis of water institutions in India. Application of a New.

[2] Harsha, K., Reddy, K.K.K. and Kala, K.S., 2015. Seismic Analysis and Design of INTZE Type Water Tank. International Journal of Science Technology and Engineering, ISSN.

[3] Walde, N.N., Manchalwar, S. and Khedikar, A., 2015. Seismic analysis of water tank considering effect on time period. IJRET: International Journal of Research in Engineering and Technology, 4.

[4] Veeraboina, P. and Ratnam, G.Y., 2012. Analysis of the opportunities and challenges of solar water heating system (SWHS) in India: Estimates from the energy audit surveys \& review. Renewable and Sustainable Energy Reviews, 16(1), pp.668-676.

[5] Bajpai, O., Mishra, S., Mohan, N., Mohan, J. and Gupta, R.K., 2013. Physico Chemical Characteristics of Lakhna Devi Temple Water Tank, Lakhna, Bakewar, Etawah, UP with reference to Cyanobacterial Diversity. International Journal of Environment, 1(1), pp.20-28.

[6] Issar Kapadia, Purav Patel, Nilesh Dholiya and Nikunj Patel (2017). "Design, Analysis and Comparison of Underground Rectangular water tank by using STAAD Provi8 software". International Journal of Scientific Development and Research (IJSDR), January 2017, Volume 2, Issue 1, ISSN: 2455-2631.

[7] B.V. Ramana Murthy, M Chiranjeevi."Design of Rectangular Water Tank by Using Staad Pro Software". -International Journal of Computer Science information and Engg., Technologies, issue 6-volume 1, series 3, ISSN 2277-4408.

[8] Thalapathy. M, Vijaisarathi. R. P, Sudhakar. P, Sridharan. V, Satheesh. V. S(2016). "Analysis and Economical Design of Water Tanks". International Journal of Innovative Science, Engineering \&Technology, Vol. 3, Issue 3,ISSN 2348 - 7968.

[9] Nallanathel. M, Ramesh. B, Jagadeesh. L(2018). "Design and Analysis of Water Tanks using Staad Pro". International Journal of Pure and Applied Mathematics, Vol.119, No.17, 021-3029 pp, ISSN: 1314-3395

(on-lineversion).url: http://www.acadpubl.eu/hub/ Special Issue.

[10] Nikunjr. P, Mistry. J., "Analysis of Circular Water Tank Stresses Under Hydrostatic Loading by Using Stadd Pro Software". Indian Journal of Research, Vol. 5, Issue 9, September 2016.

[11] Dubey. D., Dubey. S., Bajpai.Y.K., "Wind Force Analysis of Intze Type Water Tank in Various Wind Zones Using STAAD-PRO". International Journal of Advance Engineering and Research Development, Volume 4, Issue 6, June -2017, e-ISSN (O): 23484470, p-ISSN (P): 2348-6406.

[12] Patel Kulvendra. "Wind and Seismic Analysis of Elevated Tank using Staad Pro". International Research Journal of Engineering and Technology, Vol. 05, Issue 10, Oct 2018, e-ISSN: 2395-0056, pISSN: 2395-0072. 
[13] KavitiHarsha, K.S.K.Karthik Reddy, Kondepudi Sai Kala, "Seismic Analysis and Design of INTZE Type Water Tank", International Journal of Science Technology \& Engineering, Volume 2, Issue 03, Sept-2015.

[14] Smt. Dhotre, Chandrakala and Jawalkar G.C, "Analysis on Overhead Circular water tank for various bearing capacity with sloping ground", International Journal of Scientific \& Engineering Research, Volume 6, Issue 5, ISSN: 2229-5518, May-2015.

[15] Bhandari.M , Karan Deep Singh, "Economic Design of Water Tank of Different Shapes With Reference To IS: 3370-2009”, International Journal of Modern Engineering Research (IJMER), Volume 4, Issue 12, ISSN: 2249-6645, Dec-2014.
[16] Bhandari .M , Karan Deep Singh, "Comparative Study of Design of Water Tank With Reference to IS 3370", International Journal of Emerging Technology and Advanced Engineering, Volume 4, Issue 11, ISSN: 2250-2459, Nov-2014.

[17] Ranjit Singh Lodhi, Dr.Abhay Sharma, Dr.Vivek Garg, "Design of Intze Tank in Perspective of Revision of IS :3370", International Journal of Scientific Engineering and Technology, Volume No.3, Issue No.9, pp:1193-1197, ISSN :2277-1581, Sep-2014.

[18] Neeta .K Meshram, Dr. P. S. Pajgade, "Comparative Study of Water Tank Using Limit State Method and Working Stress Method", International Journal of Research in Advent Technology, Volume 2, Issue 8, ISSN: 2321-9637, Aug-2014. 